\title{
High cassava production and low dietary cyanide exposure in mid-west Nigeria
}

\author{
Adeyinka Onabolu ${ }^{1,2, *}$, Mpoko Bokanga ${ }^{1}$, Thorkild Tylleskär ${ }^{3}$ and Hans Rosling ${ }^{2}$ \\ 'International Institute of Tropical Agriculture (IITA), c/o L.W. Lambourn \& Co., 26 Dingwall Road, Croydon CR9 \\ 3EE, UK: ${ }^{2}$ Division of International Health, Department of Public Health Sciences, Karolinska Institute, SE-171 76 \\ Stockholm, Sweden: ${ }^{3}$ Department of Medicine, Nutrition Unit, Uppsala University, Dag Hammarskiölds väg 21, SE- \\ 75237 Uppsala, Sweden
}

Submitted 8 December 1999: Accepted 2 June 2000

\begin{abstract}
Objective: To investigate if high cassava production levels indicate high consumption and high dietary cyanide exposure in three villages situated within the area of Nigeria with higher cassava production than predicted by a geographic model for cassava production in Africa.

Design: Exploratory assessment of: cassava production and processing by qualitative research methods and quantification of residual cyanogens in products; cassava consumption by food frequency and weighed food records and dietary cyanide exposure by urinary thiocyanate and linamarin.

Setting: Rural communities of Afuze, Ebue and Ofabo in mid-west Nigeria.

Subjects: 110 subjects from 42 households in three villages for food frequency interviews; 118 subjects in nine Ofabo households for weighed food records.

Results: Cassava cultivation was reported to have increased in the preceding 20 years. It was consumed daily by 37 (88\%) households, but its mean contribution to daily energy intake was only $13 \%(\mathrm{SD}=10)$. The range of residual cyanogens in cassava foods was 0 to $62 \mathrm{mg}$ HCN equivalent/kg dry weight (dw). Ten samples (19\%) had levels above the $10 \mathrm{mg} \mathrm{HCN}$ equivalent/kg dw FAO/WHO safety limit. Mean urinary thiocyanate and linamarin were $51(\mathrm{SD}=35)$ and $20(\mathrm{SD}=11) \mu \mathrm{mol} / \mathrm{L}$, indicating low cyanogen intake and dietary cyanide exposure.

Conclusion: High cassava production levels did not result in high consumption and high dietary cyanide exposure levels, therefore cassava production levels cannot be used to predict consumption or cyanide exposure levels in the study area. A large part of the production is explained by intensive sales.
\end{abstract}

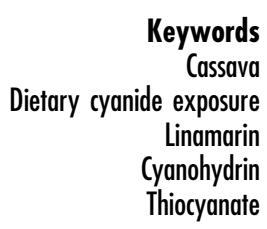

Cassava (Manibot esculenta esculenta) ${ }^{1}$ is widely grown in the tropics for its starchy roots and leaves, which are cheap sources of dietary energy and of protein, respectively. Cassava roots contain the cyanogenic glucosides, linamarin and lotaustralin, the levels of which depend on both genetic and environmental factors. Its toxicity is primarily related to the release of hydrogen cyanide (HCN) following hydrolysis of the glucosides by endogenous $\beta$-glucosidases ${ }^{2}$. When cassava tissues are disrupted, as occurs during processing, glucose and cyanohydrins are formed from the glucosides. At $\mathrm{pH}$ above 5, cyanohydrins spontaneously break down to ketones and $\mathrm{HCN}^{2,3}$. The cyanogenic glucosides and their breakdown products, cyanohydrins and HCN (jointly referred to as cyanogens), can be reduced to safe levels through various processing methods ${ }^{4-7}$.
Ingested glucosides are partly hydrolysed in the gut whereas ingested cyanohydrins and those formed during digestion are believed to completely break down to HCN, which is rapidly absorbed ${ }^{8-10}$. In humans, cyanide is metabolised to thiocyanate (SCN), by rhodanese, an enzyme occurring in most organs. The ability of the body to convert HCN to SCN is dependent on the availability of sulphur, which is derived from dietary sulphur amino acids ${ }^{11}$. Low intake of sulphur amino acids may therefore reduce the cyanide detoxification capacity of the human body. At serum levels above 250$450 \mu \mathrm{mol} / \mathrm{L}$, thiocyanate is rapidly excreted into the urine $^{11}$. The use of urinary thiocyanate as a biomarker of dietary cyanide exposure is well established ${ }^{12,13}$.

Health problems, which have been attributed to high dietary cyanide exposure, include acute poisonings ${ }^{8,14}$, 


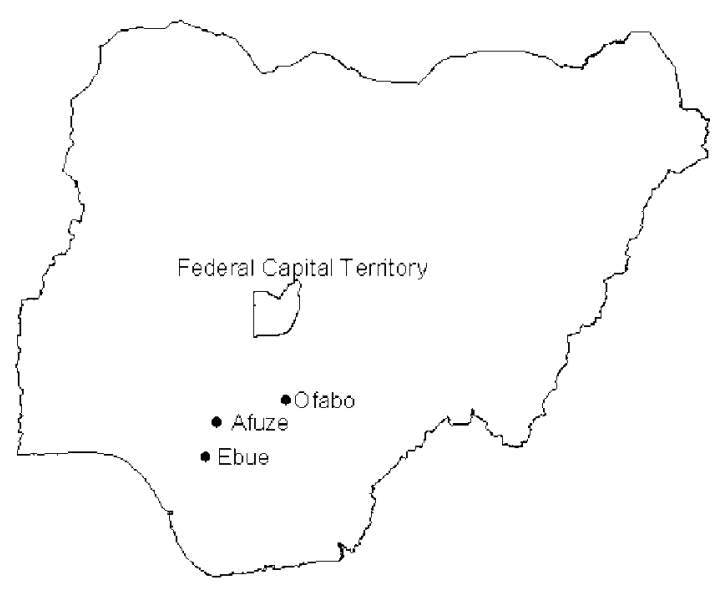

Fig. 1 Map of Nigeria showing the study villages

the paralytic disease konzo ${ }^{15}$, tropical ataxic neuropathy (TAN) $)^{16,17}$ and aggravation of iodine deficiency disorders ${ }^{18}$.

An explanatory geographic model built for the distribution of cassava in Africa, based on soil fertility, length of dry season, altitude and population density, identified six areas with high residuals indicating higher cassava production levels than predicted by the model ${ }^{19}$. Of the six areas, three are situated in Tanzania, one in northern Mozambique, one in former Zaire, and one in mid-western Nigeria. High cassava consumption and high dietary cyanide exposure have been reported from five of these areas ${ }^{8,9,20}$, but no information is available for the area in Nigeria. This study was therefore carried out to investigate if high cassava production levels indicate high consumption and high dietary cyanide exposure levels in three villages situated within the area of Nigeria with higher cassava production than predicted by the geographic model for cassava production in Africa.

\section{Methods}

\section{Study area}

The map with observed versus predicted cassava production in Africa $^{19}$ was overlaid onto the map of Nigerian villages randomly sampled for the 'Collaborative Study of Cassava in Africa' (COSCA $)^{21,22}$. The three villages included in the COSCA study within the area with higher than expected cassava production were selected for this study (Fig. 1). The villages, which are mainly farming communities, have also been designated as major cassava producing areas by the COSCA study ${ }^{23}$. From the census list compiled by COSCA, Afuze (Ojavum-Emai) had a population of about 450 persons, Ebue 900 and Ofabo 1800 persons ${ }^{24}$. The access road to Afuze was tarred, but those to Ebue and Ofabo were dirt roads. The main source of water supply in Afuze and Ebue were wells, while in Ofabo, it was a stream about $1 \mathrm{~km}$ from the village. The societies of Afuze and Ebue are monogamous, whereas Ofabo was polygamous, with men having up to four wives.

\section{Cassava cultivation, processing and consumption}

The cassava cultivation, processing and consumption patterns were documented from observations, group discussions and key informant interviews in all the villages $^{12}$. Every ninth household was selected from the census lists compiled for each of the villages by $\operatorname{COSCA}^{24}$ for participation. Of the selected 50 households, eight declined participation due to various commitments such as helping out on someone's farm or travelling out of the village. The remaining 42 were included in the study. A 24item food frequency questionnaire ${ }^{25}$, with seven cassavaderived foods, was administered in pidgin English (the lingua franca of the area) to the women responsible for cooking in each household. The food list was based on an initial rapid survey of foods consumed in the three villages.

A 3-day weighed food record ${ }^{26}$ was carried out in nine randomly selected households in Ofabo, to estimate the contribution of the different staple foods to the daily energy intake. All raw food ingredients as well as the final composite dishes were weighed and recorded. The portions consumed by each household member were weighed, and all foods left over from meals were also weighed and subtracted from the served portions. Intake of snacks outside the homes were inquired and noted. The total fats, energy and protein intakes and the fraction of total daily energy provided by cassava and other staples were calculated for each subject using a template written in Microsoft Excel.

\section{Determination of residual cyanogens in cassava food products}

Of the 42 households, 36 had enough cassava food products to provide a total of 54 ready and semi-ready to eat cassava food product samples for residual cyanogen determination. Of each sample, $30 \mathrm{~g}$ was immediately weighed into $250 \mathrm{ml}$ cold $0.1 \mathrm{M}$ orthophosphoric acid, transported on ice to the International Institute of Tropical Agriculture (IITA) laboratory and kept at $4^{\circ} \mathrm{C}$ until analysis. Cyanogens were extracted by homogenising the cassava food samples in the orthophosphoric acid. After centrifugation, total cyanogens were determined in the supernatant as HCN following hydrolysis of the cyanogenic glucosides with linamarase $\mathrm{e}^{27}$ extracted from cassava root rind ${ }^{28}$.

\section{Estimation of dietary cyanide exposure}

In the 42 households where the food frequency interviews were conducted, casual morning urine samples were collected from all 110 women and children above 2 years of age. Men were excluded because they left to work in the fields before dawn. In the nine households where the weighed records were done, casual morning urine samples were also collected following the completion of the 3-day weighed food record from all 78 children aged 6-12 years. Women were excluded as the study coincided with a major market day when they left for the market before dawn. All urine samples were transported on ice, frozen within $2 \mathrm{~h}$ of 
Table 1 Mean (SD) number of servings of various foods in the week preceding study and mean (SD) urinary biomarkers in study villages

\begin{tabular}{lcclc}
\hline & Afuze & Ebue & Ofabo & Total \\
\hline Number of households & 8 & 12 & 22 & 42 \\
Number of persons & 35 & 25 & 50 & 110 \\
Servings in preceding 7 days & & & & \\
Cassava & $14(3)$ & $15(4)$ & $13(6)$ & $14(5)$ \\
Yam & $11(6)$ & $13(6)$ & $14(6)$ & $13(6)$ \\
Rice & $4(2)$ & $7(4)$ & $3(3)$ & $4(5)$ \\
Maize & $10(4)$ & $5(4)$ & $19(10)$ & $12(10)$ \\
Oil seeds/nuts & $13(5)$ & $12(4)$ & $16(5)$ & $14(5)$ \\
Fish/meat & $17(10)$ & $13(6)$ & $16(9)$ & $15(8)$ \\
Urinary biomarkers & & & & \\
Thiocyanate $(\mu \mathrm{mol} / \mathrm{L})$ & $41(32)$ & $40(21)$ & $61(41)$ & $51(35)$ \\
Linamarin $(\mu \mathrm{mol} / \mathrm{L})$ & $17(10)$ & $15(5)$ & $23(14)$ & $20(11)$ \\
Inorganic sulphate (mmol/L) & $8(6)$ & $7(2)$ & $6(4)$ & $7(4)$ \\
\hline
\end{tabular}

collection and stored at $-80^{\circ} \mathrm{C}$ until analysis. Linamarin in urine was separated from interfering compounds by solidphase extraction on a silica column containing cyclohexyl functional groups, which retained linamarin. After elution from the column with $35 \%(\mathrm{v} / \mathrm{v})$ aqueous methanol, linamarin was hydrolysed, using linamarase and estimated as $\mathrm{HCN}^{29}$. Thiocyanate was adsorbed on a weak anionexchange resin with strong affinity for chaotropic ions, and eluted with sodium perchlorate. Thiocyanate was then chlorinated with hypochlorite and quantified according to the König reaction by the use of isonicotinic acid and 1,3dimethyl-barbituric acid ${ }^{30}$. Urinary inorganic sulphate was determined as barium sulphate by turbidimetry ${ }^{31}$. Double blind determinations of thiocyanate, linamarin and inorganic sulphate in 10 urine samples yielded correlation coefficients of $0.99,0.99$ and 0.90 , respectively.

\section{Statistical analyses}

Bivariate correlations and analysis of variance were performed on the data collected and generated, using SPSS $^{\circledR} 9.0$ for Windows (SPSS Inc., Chicago, USA).

\section{Results}

\section{Cassava production, processing and consumption}

Cassava production was reported to have increased tremendously in the preceding 20 years, replacing rice as the major cash crop in all three villages. Farmers in the three villages cultivated mostly what they referred to as the 'dangerous' cultivar, the roots of which had to be processed prior to consumption to avoid poisoning. In Ofabo the cultivation of 'non-dangerous' cultivars was reported. Roots from these were mainly eaten boiled and pounded together with yam. Fresh cassava roots, mainly of the 'dangerous' type, were traded in all three villages. Traders came in trucks to the fields and loaded the roots immediately after harvesting for sale to processors.

Four major food products were made from cassava in the three villages. Gari was the most important for trade, whereas akpu, alibo and pupuru were mainly made for home consumption. Gari is a free flowing granular cassava food product, made by grating fresh roots and fermenting the resulting mash in sacks for 48 to $96 \mathrm{~h}$ (usually $72 \mathrm{~h}$ ). The fermented mash is dewatered for about 30 min using a mechanical press. The resulting cake is pulverised, sifted, and dry roasted in earthenware or metal pots. Gari is eaten either soaked in cold water, or stirred into boiling water to make a dumpling-like product called eba. Akpu is made from a wet mash produced following the sieving of fermented, soaked cassava roots. The mash is moulded into small balls, steamed, pounded, steamed again, and then re-pounded before eating. Alibo is made by sun drying fermented, soaked cassava roots. The dried root pieces are milled into flour and prepared for eating by stirring into boiling water to make stiff dough. In Ofabo, alibo is also produced by drying fresh roots cut into small pieces. Pupuru, which is consumed only in Ofabo, is produced by grating peeled cassava roots and moulding the mash into balls about $15 \mathrm{~cm}$ in diameter. The balls are smoked over the fireplace until dried. To prepare pupuru for eating, the black outer surface of the balls is scraped, the ball pulverised and milled into flour. The flour is then stirred into boiling water to make a stiff dough.

The frequencies of consumption of the major foods eaten in the three villages are presented in Table 1. Cassava food products were eaten at least once a day by 37 (88\%) of the 42 households. Yam was stated to be the main staple in all three villages. The main oil seeds and legumes consumed were cowpeas, bambara nuts and melon seeds. Ground dried fish was a regular soup ingredient in all three villages, and was eaten at least once a day by all households.

The number of persons in the nine households in which the weighed food record was conducted ranged from 5 to 31, with a mean of 14 and a total of 118 persons. The percentage of daily energy intake from the various food staples and the intake of various macronutrients are presented in Table 2. The percentage contribution of cassava to daily energy intake ranged from 2 to $48 \%$, with a mean of $13(\mathrm{SD}=10)$.

\section{Residual cyanogens in cassava food products}

The residual total cyanogens in the various food samples collected from the households ranged from 0 to $62 \mathrm{mg}$ $\mathrm{HCN}$ equivalent $/ \mathrm{kg}$ dry weight (dw) (Table 3 ). Eight gari and two alibo samples had cyanogen levels above the $10 \mathrm{mg}$ HCN equivalent/kg dry weight safety limit of FAO/ $\mathrm{WHO}^{32}$.

\section{Dietary cyanide exposure}

The mean (SD) levels of urinary thiocyanate, linamarin and inorganic sulphate for the three villages are presented in Table 1 . The mean urinary linamarin and thiocyanate of the 78 children from the nine households in Ofabo that participated in the weighed food records were $22(\mathrm{SD}=$ 20) $\mu \mathrm{mol}$ and $56(\mathrm{SD}=50) \mu \mathrm{mol} / \mathrm{L}$, respectively. The 
Table 2 Mean (SD) daily macronutrient intake by persons in the nine households in Ofabo where the weighed food records were conducted

\begin{tabular}{lccc}
\hline & $\begin{array}{c}\text { Adult females } \\
n=28\end{array}$ & $\begin{array}{c}\text { Adult males } \\
n=21\end{array}$ & $\begin{array}{c}\text { Children }(\leq 18 \text { yrs) } \\
n=69\end{array}$ \\
\hline Mean age in years (SD) & $31.4(7.7)$ & $34.0(13.5)$ & $8.4(4.6)$ \\
Protein intake/day (g) & $23.0(14.3)$ & $25.2(19.7)$ & $18.9(10.4)$ \\
Fat intake/day (g) & $23.5(30.8)$ & $49.8(25.4)$ & $42.0(19.0)$ \\
Carbohydrate intake/day (g) & $411.2(106.3)$ & $465.6(144.3)$ & $295.3(91.8)$ \\
Energy intake/day (kcal) & $2154(559)$ & $2381(759)$ & $1596(463)$ \\
Energy intake in 3 days (\%) from & $13.0(7.9)$ & $15.7(10.2)$ & $12.7(10.4)$ \\
Cassava & $42.4(13.7)$ & $40.6(16.5)$ & $38.2(13.9)$ \\
Yam & $5.5(2.6)$ & $5.1(3.4)$ & $5.9(3.1)$ \\
Rice & $5.1(5.1)$ & $6.3(6.6)$ & $5.4(6.1)$ \\
Maize & & & \\
\hline
\end{tabular}

relationships between percentage daily energy intake from cassava and urinary linamarin and thiocyanate in these 78 children are shown in Figs $2 \mathrm{a}$ and $2 \mathrm{~b}$. There was a positive statistically significant correlation between percentage contribution of pounded yam/cassava to daily energy intake and urinary linamarin $(r=0.36, P<0.01)$ and thiocyanate $(r=0.47, P<0.01)$. There was also a positive correlation between urinary linamarin and thiocyanate for the three villages, and also for the nine households in Ofabo where the weighed food records were done $(r=$ $0.91)$.

\section{Discussion}

In contrast to most of the earlier assessments of dietary cyanide exposure from cassava in Africa ${ }^{8,13,33-37}$, this study at the same time and in the same population quantified the cassava consumption levels, the cyanogen content of the cassava foods consumed, and the levels of urinary biomarkers for dietary cyanide exposure. Cassava production and sales were observed to be high, consumption was frequent, but quantities consumed were found to be relatively small.

The cassava production levels and intensive sales observed in the present study are in agreement with previous studies in the area ${ }^{23,38}$. Intensive trading with cassava, as found in this study, is common to all the areas with higher cassava production than predicted by the geographic model ${ }^{20,34,35,37,39}$, explaining a large part of the production levels. Cassava processing in the three villages appeared effective in the removal of cyanogens, as the residual cyanogen levels in most of the food products were

Table 3 Total cyanogens (mg HCN equivalent/kg dry weight) in cassava food products consumed in the three villages

\begin{tabular}{lccc}
\hline Food product & No. of samples & Mean (SD) & Range \\
\hline Gari & 30 & $9.5(6.2)$ & $2.8-22$ \\
Eba & 7 & $5.5(3.9)$ & $0-9.6$ \\
Akpu & 4 & $2.5(2.4)$ & $0.2-5.8$ \\
Alibo & 10 & $11.6(18.5)$ & $0.5-62.2$ \\
\hline
\end{tabular}

lower than the maximum allowable limit of $10 \mathrm{mg} \mathrm{HCN}$ equivalent/ $\mathrm{kg} \mathrm{dw}{ }^{32}$.

The differences in documented cassava consumption by the food frequency method and the weighed food record are not unusual, as the problem of overestimation is well known in food frequency questionnaires ${ }^{26}$. The use of the information from the food frequency data would have resulted in an overestimation of the contribution of cassava to the daily energy intake in this population.

Urinary thiocyanate is used as a relevant measure of dietary cyanide exposure and urinary linamarin as a measure of the intake of intact glucosides ${ }^{20,40,41}$. However, in using thiocyanate as a marker for dietary cyanide exposure, it is important to assess the intake of proteins rich in sulphur amino acids, as the conversion of cyanide to thiocyanate requires sulphane sulphur from dietary sulphur containing amino acids ${ }^{11}$. The mean urinary inorganic sulphate level recorded in the study suggests a reasonable level of sulphur intake ${ }^{35}$, which could be assumed to have been supplied by the intake of fish which was frequent in all three villages. The cyanide detoxification capacity of the studied subjects could therefore be assumed to be adequate.

The urinary thiocyanate and linamarin levels found in this study are compatible with modest intakes of cyanogens from cassava and are comparable to levels reported in populations consuming cassava products with low residual cyanogens in Dar-Es-Salaam, Tanzania ${ }^{41}$ and Kinshasa in the Democratic Republic of Congo (formerly Zaire) ${ }^{36}$. The normal excretion level of linamarin is not known, but urinary excretion values as high as 614 and $657 \mu \mathrm{mol} / \mathrm{L}$ have been reported in cassava consuming populations in the Democratic Republic of Congo ${ }^{35}$, where epidemics of the paralytic disease konzo have been reported. A urinary thiocyanate level above $100 \mu \mathrm{mol} / \mathrm{L}$ has been used as an indication of high dietary cyanide exposure ${ }^{42}$. The observed urinary thiocyanate and linamarin levels in the study population suggest a mild to moderate level of dietary cyanide exposure.

The absence of a correlation between percentage contribution of all cassava foods to daily energy intake and urinary thiocyanate and linamarin (Figs $2 \mathrm{a}$ and 2b), 

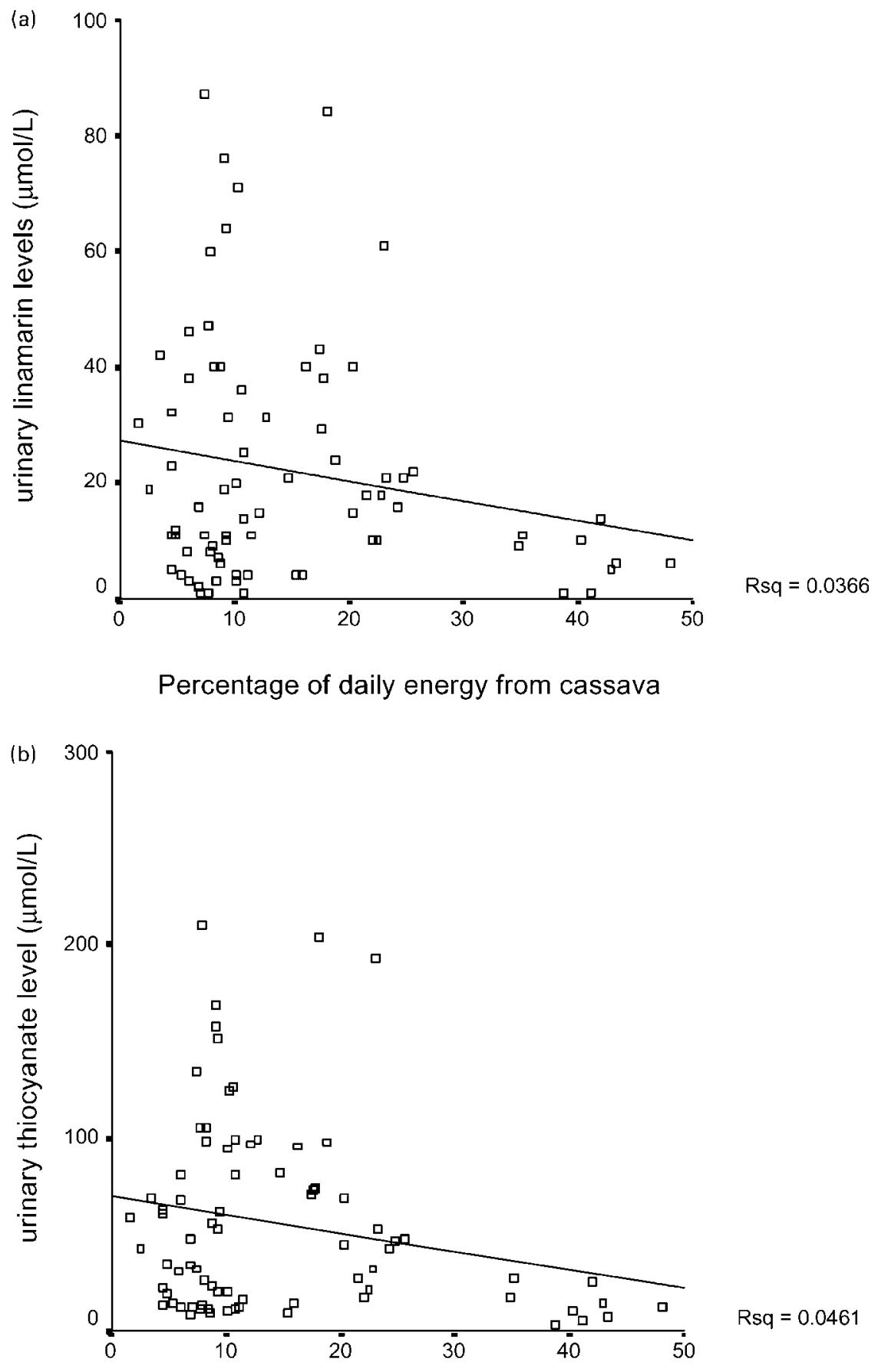

Percentage daily energy from cassava

Fig. 2 Urinary linamarin (a) and thiocyanate (b) levels in relation to percentage of daily energy intake from cassava for 78 children from nine households in Ofabo

suggests that the quantity of cassava eaten alone could not explain the modest level of dietary cyanide exposure observed in this population. The lack of association between the contribution of gari and alibo to daily energy intake is compatible with the findings of low cyanogen levels in the samples of these cassava food products. The positive significant correlations between the percentage contribution of pounded yam/cassava to daily energy intake and urinary thiocyanate and linamarin suggest that the consumption of these foods was related to the level of dietary cyanide exposure observed. This finding suggests that the cassava roots mixed with yam, referred to by the population as 'non-dangerous', must have contained high levels of cyanogenic glucosides which were probably 
broken down in the gut and detoxified to thiocyanate ${ }^{13,37}$. This assumption is further strengthened by the significant positive correlation between urinary thiocyanate and linamarin, thus suggesting a role for residual cyanogen levels of cassava foods in dietary cyanide exposure ${ }^{8}$.

Analysis of variance and post-hoc comparisons of the contribution of various cassava foods to the daily energy intake and urinary inorganic sulphate of men, women and children (not presented) showed no differences between the groups. Exposure to dietary cyanogens and the detoxification capacity of the body for cyanide would therefore be expected to be similar in all three groups. The non-inclusion of the men in the urine collection exercise would therefore not be expected to introduce a bias to the level of dietary cyanide exposure documented in this population.

\section{Conclusion}

Cassava production and sales were found to be intensive in the study area. Its consumption was frequent, but quantities consumed were relatively small. Cyanogen levels in foods were low, indicating the effectiveness of the cassava processing methods used. Consumption of cassava thus resulted in mild to moderate dietary cyanide exposure levels.

The cassava cultivars referred to as 'non-dangerous', which are pounded together with yam in Ofabo, would require screening for cyanogenic glucoside levels. This is because an increase in the proportion of cassava in the mixture may lead to a high intake of residual cyanogens, resulting in high dietary cyanide exposure levels, with the preferential use of body sulphur for cyanide detoxification. This may result in the alteration of body processes and health problems associated with high dietary cyanide exposure levels.

It is therefore concluded that cassava consumption and dietary cyanide exposure levels could not be predicted from production levels in this area of Nigeria.

\section{Acknowledgement}

This study was funded as an individual study for 10 credit points by the Swedish Missionary Council through the Department of Medicine (Nutrition Unit), Uppsala University, Uppsala, Sweden.

\section{References}

1 Allem A. The origin of Manihot esculenta Crantz (Euphorbiaceae). Gen. Res. Crop Evol. 1994; 41: 133-50.

2 Conn E. Cyanogenic compounds. Annu. Rev. Plant Physiol. 1980; 31: 433-51.

3 Bokanga M. The cyanogenic potential of cassava. In: Root Crops for Food Security in Africa, Fifth Triennial Symposium of the International Society for Tropical Root Crops-Africa Branch, Uganda, 1994, 1992. Ibadan, Nigeria: ISTRC-AB.
4 Dufour D. Effectiveness of cassava detoxification techniques used by indigenous peoples in NW Amazonia. Intersciencia 1989; 14: 86-91.

5 Vasconcelos A, Twiddy D, Westby A, Reilly P. Detoxification of cassava during gari preparation. Int. J. Food Sci. Technol. 1990; 25: 198-203.

6 Westby A, Choo B. Cyanogen reduction during lactic acid fermentation of cassava. Acta Hortic. 1994; 375: 209-15.

7 Onabolu A, Bokanga M, Rosling $\mathrm{H}$. Cassava processing in a Nigerian community affected by a neuropathy attributed to dietary cyanide exposure. Trop. Sci. 1999; 39: 129-35.

8 Mlingi N, Poulter N, Rosling $\mathrm{H}$. An outbreak of acute intoxications from consumption of insufficiently processed cassava in Tanzania. Nutr. Res. 1992; 12: 677-87.

9 Brimer L, Rosling H. Microdiffusion method with solid state detection of cyanogenic glycosides from cassava in human urine. Food Chem. Toxicol. 1993; 31: 599-603.

10 Carlsson L, Mlingi N, Juma A, Ronquist G, Rosling H. Metabolic fate in humans of linamarin in cassava flour ingested as stiff porridge. Food Chem. Toxicol. 1999; 37: 307-12.

11 Schulz V. Clinical pharmacokinetics of nitroprusside, cyanide, thiosulphate and thiocyanate. Clin. Pharmacokinetics 1984; 9 239-51.

12 Rosling $\mathrm{H}$. Measuring effects in humans of dietary cyanide exposure from cassava. Acta Hortic. 1994; 375: 271-83.

13 Tylleskär T, Banea M, Bikangi N, Cooke R, Poulter N, Rosling $\mathrm{H}$. Cassava cyanogens and konzo, an upper motoneuron disease found in Africa. Lancet 1992; 339: 208-11.

14 Akintonwa A, Tunwashe OL. Fatal cyanide poisoning from cassava-based meal. Hum. Exp. Toxicol. 1992; 11: 47-9.

15 Rosling H, Tylleskar T. Konzo. In: Shakir R, Newman P, Poser C, eds. Tropical Neurology. London: Saunders, 1996: 353-64.

16 Monekosso GL. Clinical epidemiologic observations on an ataxic syndrome in Western Nigeria. Trop. Geogr. Med. 1964; 4 316-23.

17 Osuntokun B, Monekosso G, Wilson J. Relationship of a degenerative tropical neuropathy to diet report of a field survey. Br. Med.J. 1969; 1: 547-50.

18 Delange F, Ekpechi L, Rosling H. Cassava cyanogenesis and iodine deficiency disorders. Acta Hortic. 1994; 375: 289-93.

19 Carter S, Jones P. A model of the distribution of cassava in Africa. Appl. Geogr. 1993; 13: 353-71.

20 Tylleskär T, Banea M, Bikangi N, Fresco L, Persson LÅ, Rosling H. Epidemiological evidence from Zaire for a dietary aetiology of konzo, an upper motor neuron disease. Bull. World Health Org. 1991; 69: 581-90.

21 Nweke F. COSCA Project Description. Ibadan: International Institute of Tropical Agriculture, 1988.

22 Carter S, Jones P. COSCA Site Selection Procedure. Ibadan: International Institute of Tropical Agriculture, 1988.

23 Ugwu B, Ajobo O, Orkwor G. Cassava research, production and utilization in Nigeria. In: Nweke F, Lynam J, Prudencio C, eds. Status of Data on Cassava in Major Producing Countries of Africa: Cameroon, Cote d'Ivoire, Ghana, Nigeria, Tanzania, Uganda and Zaire. Vol. COSCA Working Paper No. 3. Ibadan: International Institute of Tropical Agriculture, 1989.

24 Folayan S. COSCA Village Level Survey Database. Ibadan: International Institute of Tropical Agriculture, 1993.

25 Willet W, Sampson L, Stampfer M. Reproducibility and validity of a semi-quantitative food frequency questionnaire. Am. J. Epidemiol. 1985; 122: 51-65.

26 Bingham SA, Gill C, Welch A, et al. Comparison of dietary assessment methods in nutritional epidemiology: weighed records v. $24 \mathrm{~h}$ recalls, food-frequency questionnaires and estimated-diet records. Br. J. Nutr. 1994; 72: 619-43.

27 Essers A, Bosveld M, Van der Grift R, Voragen A. Studies on the quantification of specific cyanogens in cassava products and introduction of a new chromogen. J. Sci. Food Agric. 1993; 63 : 287-96.

28 Ikediobi C, Onyia G, Eluwah G. A rapid and inexpensive 
enzymatic assay for total cyanide in cassava and cassava products. Agric. Biol. Chem. 1980; 44: 2803-9.

29 Carlsson L, Mlingi N, Ronquist G, Rosling H. A specific and sensitive method for the determination of linamarin in urine. Nat. Toxins 1995; 3: 378-82.

30 Lundquist $\mathrm{P}$, Kågedal $\mathrm{B}$, Nilsson L. An improved method for the determination of thiocyanate in plasma and urine. Eur. J. Clin. Chem. Clin. Biochem. 1995; 33: 343-9.

31 Lundquist $\mathrm{P}$, Mårtensson J, Sörbo B, Öhman S. Turbidimetry of inorganic sulfate, ester sulfate, and total sulfur in urine. Clin. Chem. 1980; 26: 1178-81.

$32 \mathrm{FAO} / \mathrm{WHO}$. Codex standard for edible cassava flour-African Regional standard. Rome: FAO-WHO Food Standards Programme, 1992.

33 Banea M, Poulter N, Rosling H. Shortcuts in cassava processing and risk of dietary cyanide exposure in Zaire. Food Nutr. Bull. 1992; 14: 137-43.

34 Banea M, Bikangi N, Nahimana G, Nunga M, Tylleskar T, Rosling H. High prevalence of konzo associated with a food shortage crisis in the Bandundu region of Zaire. Ann. Soc. Belge Med. Trop. 1992; 72: 295-309.

35 Banea-Mayambu JP, Tylleskar T, Gitebo N, Matadi N, GebreMedhin M, Rosling H. Geographical and seasonal association between linamarin and cyanide exposure from cassava and the upper motor neurone disease konzo in former Zaire. Trop. Med. Int. Health 1997; 2: 1143-51.

36 Banea-Mayambu J, Bikangi N, Tylleskär T, Rosling H. High cassava consumption without cyanide exposure in Kinshasa, in former Zaire. Ecol. Food Nutr. 1998; 37: 363-7.

37 Mlingi N, Assey V, Swai A, McLarty D, Karlén H, Rosling H. Determinants of cyanide exposure from cassava in a konzoaffected population in northern Tanzania. Int. J. Food Sci. Nutr. 1993; 44: 137-44.

38 Nweke F. Cassava distribution in Africa. Ibadan: Collaborative Study on Cassava in Africa (COSCA), 1992.

39 Cliff J. Cassava safety in times of war and drought in Mozambique. Acta Hortic. 1994; 375: 373-8.

40 Banea M. Cassava processing, dietary cyanide exposure and konzo in Zaire. Uppsala University, 1993.

41 Mlingi N, Abrahamsson M, Yuen J, Gebre-Medhin M, Rosling H. Low cyanide exposure from consumption of cassava in Dar Es Salaam, Tanzania. Nat. Toxins 1998; 6: 67-72.

42 Lundquist P, Martensson J, Sorbo B. Ohman S. Method for determining thiocyanate in serum and urine. Clin. Chem. 1979; 25: $678-81$ 